\title{
Universidades brasileiras e seus planos de coleta seletiva
}

\author{
Joedla Rodrigues de Lima ${ }^{\mathrm{a}^{*}}$, Olga Lúcia Castreghini de Freitas Firkowski ${ }^{\text {bc }}$ \\ a Programa de Pós-Graduação em Ciências Florestais, Universidade Federal de Campina Grande, Patos, 58708-110, Paraíba, Brasil. \\ *joedlalima@yahoo.com.br \\ b Programa de Pós-Graduação em Planejamento Urbano, Universidade Federal do Paraná, Curitiba, Paraná, Brasil. \\ c Programa de Pós-Graduação em Geografia, Universidade Federal do Paraná, Curitiba, Paraná, Brasil.
}

Recebido: 21 novembro 2018 / Aceito: 13 dezembro 2018 / Publicado online: 6 janeiro 2019

\begin{abstract}
Resumo
As universidades, além de serem formadoras de profissionais, são espaços educativos que mostram como agir de forma ambientalmente responsável. O Brasil dispõe da Lei Federal 12.305/2010 e o decreto presidencial 5.940/2006 que orienta às instituições federais como realizar a coleta seletiva, incluindo encaminhamento às cooperativas de catadores. O presente artigo apresenta um panorama das universidades brasileiras em relação ao gerenciamento dos resíduos sólidos, demonstrando as experiências e as rotas desenvolvidas por estas instituições. Por meio de pesquisa documental, identificou-se que dentre 64 universidades púbicas brasileiras pesquisadas no ano de 2015, 31\% têm uma coordenadoria ou departamento responsável pela gestão dos resíduos sólidos, 33\% aderiram à agenda de sustentabilidade na gestão pública (A3P) e 71\% realizam a coleta seletiva. Dentre os resíduos mais produzidos estão o papel e material orgânico resultante de podas e cortes da grama. Destaca-se a importância do envolvimento da administração central para êxito nas ações que envolvem a coleta seletiva. É necessário prosseguir incentivando a redução e a reciclagem, seguido do diagnóstico dos resíduos gerados, o tipo, a quantidade, a(s) fonte(s) geradoras, ponto de escoamento do material, a capacidade dos depósitos, periodicidade, pessoal envolvido, suporte de veículos para transportar o material recolhido.
\end{abstract}

Palavras-chave: Agenda ambiental, resíduos sólidos, Sustentabilidade.

\section{Brazilian universities and your solid waste plan}

\begin{abstract}
Universities, the education of professionals from a plethora of fields and the providing of themselves as educational institutions which teach how to behave in an environmentally conscious. Brazil's Federal Law 12.305/2010 and the Presidential Decree 5.940/2006 guide federal institutions on how to make a selective waste collection, including its delivery to garbage collector's cooperatives. This paper aims to present an overview of how Brazilian universities manage their solid disposals waste demonstrating the experiences and routs developed by those institutions. Based on documental research it was possible to identify that amongst 64 Brazilian public universities studied in 2015,31\% are equipped with a department responsible for solid waste management, $33 \%$ have joined the sustainable public management agenda (A3P) and $71 \%$ have made selective collection. Among the most produced waste, paper and organic matter derived from pruning and grass mowing can be found. Despite of the existence of relevant actions, it was concluded that it is necessary to keep the incentives for the reduction and recycling, followed by the diagnosis of the waste generated, including type, amount, generating sources, disposal point of the matter, periodicity, people involved, and vehicle support to transport the waste collected.
\end{abstract}

Keywords: Environmental Agenda, solid wast, sustainability.

\section{Introdução}

Os profissionais que atuam no mercado de trabalho, não podem prescindir de uma formação que envolva a sustentabilidade nos seus aspectos social, econômico e ambiental, inserida tanto nas disciplinas formativas, quanto nas ações práticas no ambiente universitário.

As universidades podem ser comparadas à pequenas cidades devido a sua extensão, à população e às diversas atividades desenvolvidas, por isto ocorrem impactos ambientais negativos de diversos matizes, a exemplo da produção de resíduos sólidos inertes, resíduos químicos, eletrônicos e radioativos. Embora se verifique sistemas de gestão eficientes, o mesmo não ocorre quanto à sustentabilidade ambiental (Alshuwaikhat \& Abubakar, 2008).

Independente das políticas que atentam para as questões ambientais, em especial as relacionadas aos resíduos sólidos, as Instituições de Ensino Superior (IES) devem implementar planos de gerenciamento, tendo em vista que 
diante do papel de formação profissional, sua ação tem caráter sinérgico, por meio do qual os diversos setores da população irão desenvolver projetos desta natureza onde estiverem inseridos, reproduzindo práticas exitosas (Vega, Benitéz \& Barreto, 2008).

O Governo Federal promulgou a Lei dos Resíduos Sólidos, Lei $n^{0} 12.305$, de 02 de agosto de 2010 (Lei n. 12305, 2010), que propõe tratamento dos resíduos, priorizando por ordem de importância, a seguinte sequência: a não geração, a redução, a reutilização, a reciclagem, o tratamento dos resíduos sólidos e a disposição ambientalmente adequada dos resíduos; também instituiu a responsabilidade compartilhada, a logística reversa, cabendo ao poder público municipal desenvolver e implementar o plano integrado de gestão dos resíduos sólidos.

Especificamente nas instituições de ensino federais, antes mesmo da Lei anteriormente referenciada, o governo por meio do decreto $\mathrm{n}^{0} 5.940$, de 25 de outubro de 2006 (Decreto n. 5.940, 2006), orientava a separação dos resíduos recicláveis, sua destinação às associações e cooperativas de catadores de materiais recicláveis e instituía a comissão de coleta seletiva para gerir este processo.

Este trabalho apresenta um panorama das ações desencadeadas no âmbito das universidades, voltadas para o gerenciamento dos resíduos sólidos, bem como o percurso metodológico desenvolvido pelas mesmas, para que que sirva de orientação para se instalar, revisar ou ampliar suas atividades no setor. Esta pesquisa é reforçada pelo papel de formação profissional e multiplicador desenvolvido pelas IES e tem como objetivo reunir as experiências na coleta seletiva de resíduos sólidos nas IES e apresentar uma metodologia para implementação de um modelo de coleta seletiva visando a construção de universidades sustentáveis.

\section{Material e Métodos}

Esta pesquisa configura-se como de caráter qualitativo, exploratório, com levantamento de informações predominantemente em meio digital, utilizando a rede mundial de computadores, abrangendo todas as universidades federais brasileiras.
Inicialmente realizou-se o levantamento das IES (Tabela 1). Com essas informações encaminhou-se mensagem de email a todas as universidades solicitando as questões apresentadas abaixo, entretanto esta forma de levantamento dos dados mostrou-se ineficaz e partiu-se para a outra opção de coleta das informações via rede mundial de computadores.

\section{Coleta das informações}

Realizou-se a consulta às informações disponibilizadas na rede mundial de computadores, na própria página da IES disponível na Internet e, ou, utilizou-se de um site de busca, aplicando as três questões a seguir:

1. A universidade possui uma página especifica que trata de questões ambientais em geral, que contribua para o público interno e externo à instituição? Para esta busca digitou-se as iniciais da universidade seguido do termo ambiental ou meio ambiente. Com o seguinte arranjo: <sigla universidade> + ambiente ou <sigla universidade> + meio ambiente.

2. A universidade tem um departamento ou coordenadoria que se responsabiliza pelas atividades de implementação de práticas voltadas à coleta e destinação de resíduos sólidos gerados nas universidades?

3. Possui implementado um programa de coleta seletiva? Todas as informações obtidas para as vinte e cinco universidades pesquisadas foram armazenadas para posterior análise dos dados obtidos.

$\mathrm{Na}$ última etapa identificou-se percentualmente as universidades que são adesas à Agenda de Sustentabilidade na Administração Pública (A3P) do Ministério de Meio Ambiente e consequentemente apresentam um Plano de Gestão Logística Sustentável. A alternativa de solicitar à universidade, por meio de e-mail, as informações requeridas, mostrou-se ineficaz e foi descartada.

Tabela 1. Relação das universidades pesquisadas atuando em gestão dos resíduos sólidos (2014).

\begin{tabular}{llc}
\hline \multicolumn{1}{c}{ Estado } & \multicolumn{1}{c}{ Instituição } & Total \\
\hline $\begin{array}{l}\text { Alagoas } \\
\text { Bahia }\end{array}$ & UF de Alagoas (UFAL), UF de Alagoas (UFAL) & 2 \\
& UF da Bahia (UFBa), UF do Sul da Bahia (UFSB), UF do recôncavo & 4 \\
da Bahia (UFRB), UF do Oeste da Bahia (UFOB) & 4 \\
Minas Gerais & UF do Cariri, Universidade da Integração Internacional da Lusofonia & 4 \\
& Afro-brasileira (UNILAB), UF do Ceará (UFC) & 7 \\
Paraíba & (UFMG), UF de Ouro Preto (UFOP), UF de Viçosa (UFV), UF do \\
Pernambuco & Triângulo Mineiro (UFTM), UF dos vales do Jequitinhonha (UFVJM) & 2 \\
Piauí & UF de Campina Grande (UFCG), UF da Paraíba (UFPB) & 2 \\
Rio Grande do & UF de Pernambuco (UFPE), UFR de Pernambuco (UFRPE) & 1 \\
Norte & UF do Piauí (UFPI) & 2 \\
Sergipe & UF de Sergipe (UFS) & 1 \\
\hline
\end{tabular}




\section{Resultados e Discussão}

Os dados coletados foram organizados em etapas que constam da importância dos planos de gerenciamento de resíduos sólidos, a apresentação de diversas experiências nesta implantação e os programas de educação ambiental que servem de apoio à esta implementação.

Peculiaridades dos planos de gerenciamento dos resíduos sólidos nas universidades federais

Observa-se no ambiente universitário a necessidade de se realizar uma gestão dos resíduos sólidos em moldes sustentáveis, acompanhando a tendência mundial para alcançar maior equilíbrio ambiental, inclusive porque a mesma desenvolve atividades de formação profissional, pesquisa e extensão (Juliato \& Calvo, 2011).

Tais atividades estão voltadas, inclusive, para uso de tecnologias que impactem minimamente o ambiente, pesquisas nas áreas políticas, sociológicas, comportamental, dentre outras, importantes para a tomada de consciência e mudança de valores que exige este processo.

Barros et al. (2013) destacam que um programa de gestão dos resíduos sólidos, visa poupar os recursos naturais, como energia e matéria prima, conservação de áreas naturais, minimizar o uso dos aterros existentes, consequentemente a utilização de novas áreas para tratamento dos resíduos.

Cada Programa de Gestão dos Resíduos Sólidos (PGRS) têm suas particularidades, pois dependem dos tipos de resíduos gerados na fonte, do mercado local e da logística que se pode dispor no processo, por isto limitar-se a copiar experiências bem-sucedidas de outras instituições não é uma boa alternativa (Vega et al., 2008).

O PGRS se constitui em apenas uma etapa de ações que visam promover uma universidade sustentável ou universidade verde, esta deve se constituir por um ambiente saudável, promovido pela minimização dos impactos negativos, tais como eliminação de substâncias tóxicas; redução da geração de resíduos, de efluentes e emissões para o meio ambiente; e que promovam a saúde humana em seu conceito amplo; economia de energia e conservação de recursos; utilização de matérias primas renováveis e gestão eficiente; finalmente um ambiente de aprendizagem motivador e igualitário (Velaskez et al., 2006). Este modelo de universidade deve ser construído por meio da participação da comunidade acadêmica, inclusive porque favorece o compromisso dos envolvidos.

O Ministério do Meio Ambiente para incentivar a fomentar a sustentabilidade nas instituições públicas, criou a A3P que é a agenda ambiental na administração pública, criada em 1999, tendo em vista que elas consomem enorme quantidade de recursos naturais, de bens e serviços, propõe o desenvolvimento de ações que pautado na ética do servidor, busque eficiência e emprego de produtos que prezem a sustentabilidade ambiental e no computo geral atinja a sustentabilidade econômica (Ministério do Meio Ambiente [MMA], 2014)

Um plano de resíduos sólidos apresenta etapas e fatores imprescindíveis ao sucesso do programa. Em primeiro lugar procede-se à classificação, quantificação e respectivas fontes produtoras de resíduos. Gonçalves, Kummer, Sejas, Rauen e Bravo (2010) ressaltam a importância de se situar os locais de produção de resíduos segundo o tipo. Esta classificação deve seguir a norma NBR 10.004, que divide os resíduos sólidos em três classes distintas: Classe I são os resíduos perigosos, que apresentam periculosidade, ou uma destas características de periculosidade: inflamabilidade, corrosividade, reatividades, toxidade e patogenicidade; Classe II, são os nãoinertes, e não se classificam nas classes I ou III, estes podem ter propriedades como combustibilidade, biodegradabilidade e solubilidade em água; Classe III, são resíduos inertes que quando amostrados de forma representativa e submetidos a um contato estático ou dinâmico com água destilada ou deitonizada, à temperatura ambiente, conforme teste de solubilização não tiveram nenhum dos seus constituintes solubilizados à concentrações superiores aos padrões de potabilidade de água, excetuando-se os padrões de aspecto, cor, turbidez e sabor. Como exemplo, podem-se citar tijolos, vidros e certos plásticos e borrachas que não são decompostos prontamente (Albuquerque et al., 2010).

Destaca-se a importância de se recolher o resíduo na fonte produtora, "resíduos secos", sem estar contaminado por restos de material orgânico ou material sujo, o que o torna rejeito ou exige, a limpeza. Após esta etapa, define-se a logística do fluxo e periodicidade da coleta, a depender das instalações disponíveis para armazenamento, transporte, separação e destinação final, de acordo com o tipo de resíduo gerado (Juliatto, Calvo \& Cardoso, 2011; Gonçalves et al., 2010).

Silva, Coelho e Silva, (2012) ressaltam que se faz necessário a verificação da existência, a quantidade e respectiva capacidade dos coletores, localização e condições de conservação; a existência e o tipo de transporte disponível para as atividades de coleta do material; os locais de armazenamento temporário dos resíduos e o destino a ser dado a cada um deles. O instituto "GEA" destaca que é importante antes de começar a recolher o material identificar os receptores (http://www.institutogea.org.br/lixo/coletaseletiva, Recuperado em 29 de dezembro,2014), para evitar o acúmulo de material estocado, sem a respectiva destinação correta, portanto deve-se começar com parcimônia coletando os resíduos que contam com a destinação correta e ir ampliando gradualmente.

Na construção do plano há a necessidade de se verificar a disponibilidade de recursos humanos, bem como do efetivo envolvimento da administração central, na opinião de Gonçalves et al. (2010) e a busca de soluções que sejam exequíveis segundo as condições humanas, físicas e financeiras da instituição (Juliatto et al., 2011).

Experiências de Implantação da gestão dos resíduos produzidos em universidades e observância ao decreto federal $n^{o} 5940$ (26/10/2006)

Dentre as Universidades pesquisadas, somente a Universidade Federal do Rio Grande do Norte (UFRN) tem uma Diretoria de Meio Ambiente (DMA) vinculada à Superintendência de Infraestrutura.

Duas universidades investigadas possuíam páginas online específicas sobre meio ambiente. A Universidade Federal de Campina Grande apresentam, em seu sitio, um link direto que 
remete a uma página sobre meio ambiente, entretanto a da UF de Campina Grande (www.florestalrecicla.com) refere-se a um programa de extensão desenvolvido no Campus de Patos. A Universidade Federal do Rio Grande do Norte tinha a página denominada "UFRN meio ambiente" <www.meioambiente.ufrn.br>.

Considerando a legislação brasileira (Decreto n. 5940, 2006) conta com doze anos de publicação e a Lei dos Resíduos Sólidos com oito anos de promulgação, identificouse que, até 2014, 72\% das universidades federais da região semiárida desenvolvem projetos de coleta seletiva solidária, neste percentual se inserem as cinco universidades que não estavam listadas no site do MEC e todas são universidades recentes. Em quatro delas não há projetos nesta linha. (http://portal.mec.gov.br/pec-g/cursos-e-instituicoes, recuperado em 1 de março, 2015)

Das instituições, $31 \%$ tem um departamento ou coordenadoria que trata especificamente das questões de meio ambiente e sustentabilidade. Quanto à adesão à Agenda de Sustentabilidade na Administração Pública (A3P) identificou-se a participação de 6 universidades federais (24\%), são elas: UF da Bahia, UF da Paraíba (Campus I), UF de Campina Grande, UF do Rio Grande do Norte, UF do Vale do São Francisco, UF Rural de Pernambuco. Entretanto, não se averiguou a efetividade de tal participação.

Em relação à coleta seletiva, a coleta de resíduos sólidos secos foi o que predominou. Dentre os tipos de resíduos, a grande produção de papel nas instituições de ensino superior é confirmada pelas pesquisas realizadas por Smyth;Freedeen e Booth (2010). Por sua vez, Vega et al. (2008) realizaram a caracterização dos resíduos sólidos em universidade no México como prerrogativa básica para implantação de programa de coleta seletiva. Os autores identificaram que a maior proporção de resíduos é de papel, destes, $33 \%$ são potencialmente recicláveis, e também sua produção pode ser minimizada, pois geralmente utiliza-se apenas um lado da folha. Diante desta realidade ressalta-se a importância de se preceder a um programa de reutilização e redução do desperdício. Caso o papel fosse utilizado dos dois lados, a produção de papel seria reduzida a aproximadamente $50 \%$, além do incentivo a práticas como a comunicação por e-mail, a leitura de documentos digitais, o aproveitamento de papel para rascunho, memorandos e relatórios, nesse caso a economia seria ainda maior. Quanto aos resíduos orgânicos o maior volume refere-se àquele gerado pela poda de árvores e corte da grama.

Mason, Brooking, Oberender, Harford e Horsley (2003) apresentam a experiência com a implantação de um programa de "Lixo Zero" num campus universitário situado na Nova Zelândia, iniciou pelo estudo dos resíduos produzidos pela instituição, sua quantificação e as opções de compostagem, num segundo momento estudou-se as alternativas de separação dos resíduos na fonte, localização de coletores e containers, associados à campanha educativa.

Barros et al. (2013) ressaltam a importância de se ter representantes da comissão em cada instituto auxiliando na gestão do processo, tanto verificando o fluxo da saída dos materiais, quanto intermediando opiniões, sugestões e queixas da comunidade envolvida.
É importante destacar também a necessidade da implantação da coleta seletiva nas universidades ser precedida por fóruns para a participação da comunidade acadêmica na construção do plano, pois o mesmo deve ter as características locais. Disterheft, Caeiro, Ramos e Azeiteiro (2012) reuniram as experiências com implantação de programas de sustentabilidade em 47 universidade de 17 países da Europa e os mais bem-sucedidos, ou mais eficazes, utilizaram a técnica de planejamento participativo em vez das abordagens "top down" (modelos prontos) ou um misto das duas experiências. Entretanto o gestor do processo precisa ter um conhecimento das experiências, dos sucessos e insucessos ocorridos em outras instituições para coordenar com maior chance de êxito a implantação.

\section{Educação Ambiental como base para programas bem- sucedidos}

As faculdades e universidades têm a obrigação moral e ética de agir de forma responsável com o meio ambiente, a gestão dos resíduos sólidos além de um compromisso de responsabilidade ambiental e legal é uma forma de ensinar à comunidade universitária de que modo agir de forma ambientalmente correta em relação aos resíduos sólidos especificamente (Vega et al., 2008).

Em primeiro lugar, um plano de gerenciamento dos resíduos sólidos deve iniciar com o compromisso de diminuição da produção, reuso ou aumento de vida do produto pelo consumidor. Esta prática é difundida pelos brechós, sebos ou pontos de troca. Inclusive perpassa pelo fortalecimento das redes de artesãos que remasterizam o material, ou criam novas utilidades, fortalecendo o fluxo financeiro entre estes grupos.

O encaminhamento dos resíduos recicláveis para as cooperativas de catadores, exigência do decreto 3940/2006, é uma forma de fortalecer este setor, inclusive promovendo a melhoria da qualidade de vida dos catadores de materiais recicláveis, retirando-os do ambiente perigoso e insalubre dos lixões ou aterros controlados.

Após as etapas de redução e reuso, faz-se necessário repensar o consumo, valorizar os produtos produzidos localmente, seguida da etapa prioritariamente discutida neste artigo, qual seja, a seleção dos resíduos na fonte geradora e sua destinação às cooperativas de catadores, denominado “coleta seletiva solidária", uma particularidade da legislação brasileira.

$\mathrm{O}$ mecanismo para divulgação e incentivo à mudança de atitudes é a educação para um ambiente natural equilibrado, a Lei da Política Nacional de Educação Ambiental $n^{0}$ 9795, de 27 de abril de 1999, conceitua a educação ambiental como sendo "processos por meio dos quais o indivíduo e as coletividades constroem valores sociais, conhecimentos, habilidades, atitudes e competências voltadas para a consciência do meio ambiente e postura diante do mesmo"( Lei n. 9.795, 1999).

Navarro (2014, p. 85) afirma que a educação ambiental não deve ser reduzida a transmissão de conhecimentos, mas como um "processo criativo de formação de valores e promoção de mudanças de paradigmas, formando seres humanos conscientes de sua posição no mundo".

Este processo de tomada de consciência é discutido por 
Eduardo (2014) que enfatiza que a crise ecológica é uma crise de valores, resultado do distanciamento do ser humano em relação à natureza e, ao paradigma de desenvolvimento dominante, portanto uma educação ambiental deve estar embasada numa postura crítica do papel do ser humano e este quanto mais consciente estiver, terá mais liberdade para agir de forma comprometida eticamente.

Dentro deste enfoque Haan (2006) propõe um modelo de educação voltado para o desenvolvimento sustentável que engloba uma série de competências-chave, organizadas em oito sub-competências. Tais competências englobam o pensamento previdente; trabalhar de forma interdisciplinar; para a percepção cosmopolita, ou seja, ter entendimento de cooperações interculturais; para as habilidades participativas; para o planejamento e a implementação; para a capacidade de empatia, compaixão e da solidariedade; para motivar a si mesmo e aos outros; para refletir de forma distanciada dos conceitos individuais e culturais.

Depreende-se das posturas apresentadas anteriormente que o processo de educação ambiental envolve aprendizagens que vão além do conhecimento técnico e da interdisciplinaridade, como habilidades do campo emocional, físico e espiritual, que devem ser perseguidas pelos programas de coleta seletiva dentro de uma visão ampliada de sustentabilidade na qual os mesmos devem estar inseridos.

Albuquerque et al. (2010) asseveram que no processo de implantação da coleta seletiva na UFSC, identificou-se que para o mesmo obter sucesso deveria haver um programa de educação ambiental, e que não faltasse a ênfase nos tópicos da coleta seletiva, pois é imprescindível haver um público instruído e disposto a colaborar com o programa. Por isto o programa da UFSC inseriu vários níveis de abordagem da temática, desde o esclarecimento de questões operacionais, às discussões filosóficas tratando o assunto de forma mais aprofundada, até uma abordagem voltada a tomada de decisão para os dirigentes, numa perspectiva estratégica de longo prazo. Os citados autores acrescentam que é indispensável que o processo de conscientização envolva toda a comunidade universitária não apenas na fase de implantação, mas também, para auxiliar no processo decisório necessário à atividade de gerenciamento do processo.

\section{Conclusões}

As IES desempenham uma função peculiar em termos de coleta seletiva, que é incentivar os futuros profissionais quanto à esta prática não apenas no exercício profissional, mas também em sua seus atos cotidianos. Mais da metade das universidades federais estão comprometidas com o cumprimento do decreto 3940/2006, em níveis diferentes, inclusive, algumas com coordenadoria ou departamento responsável por tratar da gestão ambiental e que aderiram à agenda de sustentabilidade na gestão pública (A3P) do Ministério do Meio Ambiente. Verificou-se que na gestão dos resíduos sólidos, a maior produção é de papel e resíduos orgânicos provenientes de podas e cortes da grama.

As experiências demonstram que antes de iniciar a coleta seletiva, deve-se dar atenção à atitudes de redução e reaproveitamento dos mesmos, preferencialmente o Plano de Gerenciamento dos Resíduos Sólidos deve partir do diagnóstico dos resíduos gerados, incluindo o tipo, a quantidade, a(s) fonte(s) geradoras, o destino após o recolhimento, a respectiva capacidade dos depósitos e a periodicidade do recolhimento, o pessoal envolvido, o suporte de veículos para transportar o material recolhido. A dinâmica e a abrangência da atividade, as etapas do projeto, a função e as níveis de educação ambiental deve ser construído por meio de planejamento participativo para maior envolvimento da comunidade acadêmica. A prática da educação ambiental é imprescindível, tanto para capacitar a equipe técnica, quanto para sensibilizar o público envolvido e promover a mudança de paradigmas em que os resíduos sejam vistos dentro de uma lógica da mínima extração de matéria prima e produção de resíduos.

\section{Agradecimentos}

Ao Conselho Nacional de Pesquisa Científica (CNPq) pela concessão da bolsa de pós-doutorado, à Universidade Federal do Paraná pela oportunidade de realização do estágio de pósdoutorado e à Universidade Federal de Campina Grande.

\section{Referências}

Alshuwaikhat, H. M. \& Abubakar, I. (2008). An integrated approach to achieving campus sustainability: assessment of the corrente campus environmental management practices. Jornal of Clean Production, 16, 1777-1785. doi: 10.1016/j.jclepro.2007.12.002

Vega, C. A., Benitéz, S. O. \& Barreto, M. E. R. (2008). Solid waste characterization and recycling potential for a university campus. Waste Management, 28, 21-26. Doi: 10.1016/j.wasman.2008.03.022

Lei n. 12305, de 2 de agosto de 2010. Institui a Política Nacional de Resíduos Sólidos; altera a Lei no 9.605, de 12 de fevereiro de 1998; e dá outras providências. Recuperado http://www.planalto.gov.br/ccivil_03/_ato20072010/2010/lei/112305.htm.

Decreto n. 5.940, de 25 de outubro de 2006. Institui a separação dos resíduos recicláveis descartados pelos órgãos e entidades da administração pública federal direta e indireta, na fonte geradora, e a sua destinação às associações e cooperativas dos catadores de materiais recicláveis. Recuperado de http://www.planalto.gov.br/ccivil_03/_Ato20042006/2006/Decreto/D5940.htm

Araújo, F. O. \& Altro, J. L. S. (2014). Análise das práticas de gestão de resíduos na escola de engenharia da universidade federal fluminense em observância ao decreto 5940/2006 e à Lei 12.305/2006. Sistemas $e$ Gestão, 9(3), 310-326.

Juliatto, D. L., Calvo \& M. J., Cardoso, T. E. (2011). Gestão integrada de resíduos sólidos para instituições públicas de ensino superior. Revista Gual, 4(3), 170-193. doi: 10.5007/1983-4535.2011v4n3p170

Barros, R. M., Thiago Fiho, G. L., Moura, J. S. Pieroni, M. F., Vieira, F. C., Lage, L. R., ...Bastos, A. S. (2013). Design and implementation study of a permanente selective collection program (PSCP) on a university campus in Brazil. Resources, Conservation and Recycling, 80, 97-106. doi: 10.1016/j.resconrec.2013.09.005

Velazquez, L., Munguia, N., Platt, A. \& Taddei, J. (2006). Sustainable university: what can be matter? Jornal of clean Production, 14, 810 - 819.

Ministério do Meio Ambiente. Sustentabilidade na administração pública (A3P) (4a ed.). Brasília: Ministério do Meio Ambiente. Recuperado de http://www.mma.gov.br/estruturas/a3p/_arquivos/manual_a3p_4ed_rdz. pdf

Albuquerque, B. L., Rizatti Junior, G., Rizzati, G., Sarmento, J. V. S. \& Tissot, L. (2010, abril). Gestão de Resíduos sólidos na universidade federal de Santa Catarina: os programas desenvolvidos pela coordenadoria de gestão ambiental. Anais do Colóquio internacional sobre gestión universitária en América del Sur. Mar Del Plata, Argentina.

Silva, J. R. S., Coelho, B. E. N. \& Silva, J. P. (2012, novembro). Plano de gerenciamento de resíduos sólidos de uma instituição de ensino superior do estado de Goiás (pp. 1-7). Anais do Congresso brasileiro de gestão 
ambiental, Goiânia, Goiás, Brasil. Recuperdado de https://www.ibeas.org.br/congresso/Trabalhos2012/I-013.pdf

Gonçalves, M. S., Kummer, L., Sejas, M. I., Rauen, T. G. \& Bravo, C. E. C. (2010). Gerenciamento de resíduos sólidos na Universidade Tecnológica Federal do Paraná, Campus Francisco Beltrão. Revista Brasileira de Ciências Ambientais, 15, 79-87.

Smyyh, D. P., Fredeen, A. L. \& Booth, A. L. (2010). Reducing solid waste in higher educacion: The first step towards "greening" a university campus. Resources, Conservation \& Recycling, 54(11), 1007-1016. doi: 10.1016/j.resconrec.2010.02.008

Mason. I. G., Brooking, A. K., Oberender, A. Harford, J. M. \& Horsley, P. G. (2003). Implementation of a zero waste programa t a university campus. Resources, Conservation \& Recycling, 38(4), 257-269. doi: 10.1016\%2FS0921-3449(02)00147-7

Disterheft, A., Caeiro, S. S. F. S., Ramos, M. R. \& Azeiteiro, U. M. M. (2012). Environmental Management Systens (EMS) implementation processes and practices in European higher education institutions - topdowm versus participatory approaches. Jornal of Cleaner Production, 31, 80-90. doi: 10.1016/j.jclepro.2012.02.034

Puschmann, R., Azevedo, M. A., Molino, D. B., Cruz, M. C. C. \& Pinheiro, R. (2004, setembro). Projeto Reciclar, implantação de coleta seletiva no campus da UFV. Anais do Congresso brasileiro de extensão universitária. Belo Horizonte, Minas Gerais, Brasil. Recuperado de https://www.ufmg.br/congrext/Meio/Meio22.pdf

Lei $n$. 9.795, de 24 de abril de 1999. Dispõe sobre a educação ambiental, institui a Política Nacional de Educação Ambiental. Recuperado de http://www.planalto.gov.br/ccivil_03/leis/19795.htm

Navarro, G. C. (2014). Educação ambiental e resíduos sólidos. In J.R.M. Leite, G. Parente \& N. Belchior (orgs). Resíduos sólidos e políticas públicas: diálogos entre universidade, poder público e empresas (pp. 7690). Florianópolis: Insular.

Eduardo, T. J. P. (2014). A política nacional de resíduos sólidos e a implementação de usinas waste-to-energy: a sociedade de risco na atualidade. In J.R.M. Leite, G. Parente \& N. Belchior (orgs). Resíduos sólidos e políticas públicas: diálogos entre universidade, poder público e empresas (pp. 174-192). Florianópolis: Insular.

Haan, G. (2006). The BLK "21" programme in Germany: a "Gestaltungskompetenz" - based model for education for sustainable development. Environmental Education Research, 12(1), 19-31. doi: $10.1080 / 13504620500526362$

Licença Creative Commons CC BY 4.0

Este artigo foi publicado com acesso aberto para distribuíção sob os termos do Licença de Atribuição Creative Commons, que permite uso irrestrito, distribuição, e reprodução em qualquer meio, desde que o trabalho original seja devidamente citado. 